Article

\title{
The Meaning of Health, Well-Being, and Quality of Life Perceived by Roma People in West Sweden
}

\author{
Leena Eklund Karlsson ${ }^{1,2, *}$, Kristine Crondahl ${ }^{1}$, Fredrik Sunnemark ${ }^{1}$ and Åsa Andersson ${ }^{3}$ \\ 1 Department of Health, Culture and Education Sciences, University West, Gustava Melinsgata 2, \\ 46186 Trollhättan, Sweden; E-Mails: kristine.crondahl@tele2.se (K.C.); \\ fredrik.sunnemark@hv.se (F.S.) \\ 2 Institute of Public Health, University of Southern Denmark, Niels Bohrs vej 9, \\ 6700 Esbjerg, Denmark \\ 3 Department of Social Work, University West, Gustava Melinsgata 2, 46186 Trollhättan, Sweden; \\ E-Mail: asa.andersson@hv.se \\ * Author to whom correspondence should be addressed; E-Mail: leklund@health.sdu.dk; \\ Tel.:+45-6550-4158; Fax: +45-6550-4283.
}

Received: 8 April 2013; in revised form: 23 May 2013 / Accepted: 3 June 2013 /

Published: 10 June 2013

\begin{abstract}
Many Roma people in Sweden are on the margins of society and face problems of social exclusion, institutional discrimination, low education, unemployment, and poor health. The aim is to describe how a group of Roma people, in West Sweden, understand health, well-being, and quality of life within the Roma context, and how they cope with their life-situation. Data consisted of qualitative interviews. The data were analyzed qualitatively using a phenomenological hermeneutic approach. The respondents mainly understood the concept of Health as "being healthy" and "feeling good". Elements that were crucial part of the respondents' health perception were being employed, having an education, social support from family and friends, freedom and security, and the extent of involvement in society. The results indicate that the respondents perceive their health and life situation as good, despite of their marginalized situation and discrimination.
\end{abstract}

Keywords: Roma people; health perceptions; quality of life; well-being; qualitative research 


\section{Introduction}

According to Hancock [1] and the Swedish Governmental Official Report (SOU) [2], the Roma originate from North India and have been known in Europe for nearly a thousand years. Much of this time, they have been discriminated against and oppressed by the mainstream society $[3,4]$. The Roma people are the largest ethnic minority group in the European Union, comprising about 10-12 million people [3]. Approximately 50-60,000 Roma people live in Sweden [2,5]. The local Roma NGOs, however, estimate the number to be much higher as many of the Roma do not reveal their ethnicity because of the fear of stigma and discrimination. The Roma in Sweden are not a homogenous group: They consist of Travellers, Finnish Roma, Swedish Roma, Non-Nordic Roma from Hungary, Romania, Poland and Eastern Europe, and Balkan Roma from the former Yugoslavia.

The first notes of Roma people in Sweden are from the early 16th century. Ever since then, the Roma people in Sweden have been victims of discrimination, social exclusion, and oppression [4-7]. The situation for Roma in Sweden is quite similar to the situation of the Roma in other parts of Europe, though the level of exclusion may be different due to the Swedish welfare system, which ensures that no-one, including marginalized people, should fall below a certain poverty line [2]. The picture that emerges from the evidence summarized by the SOU shows that Roma in Sweden live in poorer conditions than the majority population. It is only a generation ago that Roma individuals got the right to vote and participate in elections, as well as get access to education. This has led to a situation where the Roma people in Sweden are poor in, social, economic, political, and civil welfare; and lack decision-making power to influence matters concerning them. The situation and status of the Roma minority can be characterized as a kind of curtailed citizenship rather than a situation offering possibilities of social integration and full citizenship. Sweden has experienced problems caused by racist structures that affect the entire national Roma minority, states Montesino [6]. Palmroth and Hermansson [8] claim that the marginalized situation of the Roma people is a consequence of a complex interplay between the Swedish society's rejection and the rejected, and stigmatized minority's reaction in a tendency of isolating and protecting themselves. Palmroth and Hermansson consider the Roma people to have been excluded from Swedish society, particularly from political discussions on measures and interventions planned for the group. Today, the Roma in Sweden are still largely outside the democratic process [2]. The long-lasting antiziganist policies and remaining structural discrimination have created a deep-rooted lack of trust within the Roma minority towards the state and the public institutions of the majority society [2].

In 2000, the Swedish Government ratified the European Council's Framework Convention for the Protection of National Minorities [9]. Through the convention the Roma people (along with four other Swedish national minorities) were granted national minority status in Sweden, which was intended to reinforce the possibility of persons belonging to minority groups to preserve their human rights. National minorities, by definition ([2], p. 19), are groups with a pronounced affinity with their own religious, linguistic or cultural background, along with the desire to maintain their identity. Being granted a national minority status means that the state of Sweden, by law, has a responsibility to protect and support the Roma traditions, language, religion, and culture, and to promote equality between Roma people and the majority population. However, many of the Roma people continue to be on the margins of society and still face problems of harassment, institutional discrimination, 
unemployment, low or no education, poor and overcrowded housing, and poor health status $[2,10]$. The circumstances can be summarized as social exclusion. The World Health Organization (WHO) [11] points out that the social exclusion has often been seen only as a state. However, according to Popay et al. [12] and WHO [13], social exclusion consists of dynamic, multi-dimensional processes driven by unequal power relationships...resulting in a continuum of inclusion/exclusion characterized by unequal access to resources, capabilities, and rights which leads to health inequalities. Pierson [14] defines social exclusion as a process over time that deprives individuals and families, groups, and neighborhoods of the resources required for participation in the social, economic, and political activity of society as a whole. Through this process, people are cut off from institutions and services, social networks, and developmental opportunities. Today, social exclusion can be seen as a condition of a minority of people who are marginalized from the middle mass.

Racism, discrimination, and poverty have shown to influence people's physical and mental health and well-being [15,16]. Pascoe and Smart Richman, [17] found that perceived discrimination has negative physical and mental health outcomes, and that it also heightens perceived stress. Harris et al. [18] associated discrimination with poor or fair self-rated health, lower physical functioning, lower mental health, smoking, and cardiovascular disease.

\subsection{The Health of Roma People}

There is somewhat scattered information on Roma people's health from a medical and epidemiological perspective (see e.g., [19]), but according to the research that has been done from that perspective, European Roma have worse health and a shorter life expectancy than the majority populations [20-22]. Additionally, it has been shown that European Roma have less access to healthcare services [23], higher morbidity, especially from infectious diseases [24], culture-related difficulties with healthcare providers [25-29], more lifestyle-related risk factors of health than the total population [30], more reported mental health problems [3,31], problems with reproductive health [32], and deficient degrees of vaccination [33].

The Roma Human Development Report of 2003 clearly points out that Roma health in the included survey countries (Bulgaria, the Czech Republic, Hungary, Romania, and the Slovak Republic) has worsened during the last decade [34]. The Fundación Secretariado Gitano (FSG) [35] confirms this picture in a recent inventory on the health of the Roma community in Europe. Their report concludes that poor housing, inadequate education, and difficulties in gaining access to and using healthcare services, together with deficient health habits, all contribute to the poor health status, a high morbidity rate, and a lower life expectancy of the European Roma vis-à-vis other Europeans.

Research on Roma people's own perceptions of health is scarce. According to the FSG [35], the Roma population perceives their own health to be quite similar to that of the rest of the European population: $68 \%$ of Roma consider their health to be good or very good, compared to $66 \%$ of the EU-27 population (EU-27 is the European Union of 27 Member States: Belgium, France, Germany, Italy, Luxembourg, Netherlands, Denmark, Great Britain, Ireland, Portugal, Spain, Greece, Austria, Finland, Sweden, Czech Republic, Estonia, Hungary, Latvia, Lithuania, Poland, Slovakia, Slovenia, Malta, Cyprus, Bulgaria and Romania). This might be partly explained by the fact that the Roma population in the countries studied was significantly younger than the non-Roma respondents. 
However, when the data were broken down by age the study found that $2 \%$ of the Roma population, between the ages of 15 and 24, rated their health as poor or very poor, which is a bit higher than the EU-27 population. The results are in line with the results of the earlier Roma Human Development Report of 2003 [34], which found that even though the health of the Roma was considered poor from the medical perspective, most of the respondents expressed their health, and that of their children, as "good" or "tolerable". The National Institute of Health in Sweden conducted a qualitative study in 2011 [36] on how Roma themselves view Roma health and concluded that Roma perceive health as an ideal state which they have difficulty to achieve. The study did not include statements on how the informants perceived their health at the moment of the interview, though. Crondahl and Eklund [37] showed that the Balkan Roma adolescents living in West Sweden perceive their health and well-being as good. However, looking at Roma health from a salutogenic perspective [38], using Antonovsky's Sense of Coherence-scale (SOC), the Roma SOC was ranked lower than both the Swedish majority and the Sami minority populations. Hassler and Eklund [38] claim this to be an indication of Roma people's marginalized situation in Sweden.

A known fact is that there is a lack of scientific research on the Roma in Sweden in several areas $[7,19,39]$. There is little research, particularly on the Roma's self-perception of their situation regarding important factors such as health, well-being, coping strategies, and perceptions of education related to quality of life and marginalization.

The aim of the study at hand is to describe how a group of Roma people in West Sweden understand health, well-being, and quality of life, within the Roma context, and how they cope with their life-situation. The study was the qualitative part of a baseline mapping of perceptions on health and life-situation of the Roma people in West Sweden before the start of a two-year empowerment project [40].

\section{Theoretical Underpinnings of the Study}

Several theories and models have been developed to explain the health concept. There is a general agreement that health is a positive, dynamic, and multidimensional state and not only freedom from disease. Further, health is associated with the individual's situation and context, and allows him to cope with the demands of life [41]. Consequently, health is the ability to resist the strains and stresses of physical, mental, and social nature, so that stress does not lead to reduced life span, function, or well-being $[42,43]$. For Antonovsky, health is not a healthy/sick dichotomy, but rather a continuum with the ease (health) and disease (illness) poles. A person's health or disease is determined, to a significant extent, by his general attitude towards the world and his/her own life; his sense of coherence. The more pronounced a person's SOC, the healthier he/she should be and the more quickly he/she will regain health and remain healthy. Antonovsky explains the sense of coherence concept being as a global life orientation, including three components: people's ability to comprehend what is happening around them, the extent to which they are able to manage their life situation, and the ability to find meaning in these situations.

WHO [43] defines health as "a resource for everyday life". However, for people to achieve their fullest health potential they need to be empowered to be able to take control over their own health and its determinants [43,44]. Huber et al. suggest [45] an elaborated health concept based on resilience or 
capacity to cope and maintain and restore one's integrity, equilibrium, and sense of well-being. Huber et al. view health as "the ability to adapt and to self-manage" in physical, social, and mental domains: In the physical domain a healthy organism is capable to maintain physiological homoeostasis through changing circumstances; Health in the social domain can be regarded as a dynamic balance between opportunities and limitations, shifting through life and affected by external conditions such as social and environmental challenges. By successfully adapting to an illness, e.g., people are able to work or to participate in social activities and feel healthy despite limitations. Huber et al. connect the mental domain to Antonovsky's "sense of coherence" concept by claiming that the mental domain includes a capacity to cope, recover from strong psychological stress, and prevent post-traumatic stress disorders. Coping is seen as a response to a stressor, and is claimed to be a process composed of resources, strategies and the meaning of coping [46].

Quality of Life (QoL) is a broader concept than personal health status. Lindström [47] defines QoL as the total essence of existence of an individual, a group, or a society, as measured objectively and perceived subjectively. QoL consists of global (macro environment, human rights, and policies), external (work, economy, and housing), interpersonal (family, intimate ties between child and parents, and extended networks), and personal spheres (self-esteem and basic mood). Objective conditions and perceived subjective satisfaction are included in all dimensions. Lindström sees QoL as an individual's perception of their position in life in the context of the culture and value system where they live and in relation to their goals, expectations, standards, and concerns.

The concept of well-being has been claimed to have both an affective and a cognitive component [48-50], the latter of which also has been called as general life satisfaction [50-52]. Of the two components, the affective has received wide attention by the researchers in comparison with the interest on the cognitive, the general life satisfaction [48,53]. Life satisfaction is regarded as people's judgmental processes [48] in which individuals assess their quality of life on the basis of their own unique set of criteria [54].

Gasper [51] divides well-being into two dimensions, objective and subjective well-being. Objective well-being refers to a set of collectively agreed values such as, e.g., freedom of pain and the degree of mobility, as well as constitutional factors (including physical disability) and environmental conditions in the person's life. The focus of subjective well-being is people's personal evaluation of own lives. Several studies have revealed that subjective well-being is scarcely connected to objective physical health [55], but that subjective well-being, on the other hand, is an important indicator to QoL. Diener [55] found that people's adjustment to circumstances is connected to their ability to adjust their goals in accordance with the new conditions. However, the factors that influence life satisfaction vary remarkably in different societies. People belonging to collectivist cultures have a tendency to be consulting with friends and family, and even norms, in evaluating their lives and judging whether they are satisfied with it [55].

Research on people with serious and persistent disabilities show that their perceptions of QoL (personal health and subjective well-being/life satisfaction perceived as good, are not concurrent with their disability and objective health status [56]. This has been called the disability paradox. However, in a study to examine why this is so, Albrecht and Devlieger found that disabled people who report a high QoL have gained an understanding of their condition and have made their disability to make 
sense. They see their situation as it is and set goals from there, looking for resources that will help them manage their lives.

\section{Methods}

The study focus was on adult Roma people living in the Western Region of Sweden (Västra Götaland) in 2009. The data consisted of 27 qualitative interviews with 33 Roma people, 16 women and 17 men, aged 18-64 years. At the moment of the interview, 19 out of the 33 respondents were doing adult studies to complete their primary education. Those who were studying had either never had a job or had worked occasionally in short periods. From the remaining 14, six had a job and eight were unemployed.

The Roma community is not easily accessible for a non-Roma researcher due to the Roma community's learned mistrust towards Swedish society, as stated above. Thus, the sampling was done by convenience - and snowball techniques [57,58], with the assistance of two Roma gatekeepers, with whom we had had earlier collaborations. These gate-keepers picked the first voluntary participants for the interviews. The first interviewees then suggested further interviewees among their friends, neighbors, and relatives living in the same region.

The interviews were conducted using an interview guide based on the themes found in earlier studies on health, well-being and QoL, and on the salutogenic perspective on health [42]. The interviews were conducted in interaction between the interviewer and the interviewee, as the interviewees were not always comfortable with the Swedish language. The interviews were tape-recorded and transcribed verbatim.

The data analysis was inspired by a phenomenological hermeneutical method developed by Lindseth and Nordberg [59], who base their work on Paul Ricoeur's philosophy [60]. The idea of their method is phenomenological in the sense that the researchers try to understand the experiences expressed in interview texts, which then need interpretation. The method is hermeneutical in the sense that it includes dialectic movement between understanding and explanation through reflection towards literature [59]. The method starts by formulating a 'naïve understanding' of the text in an initial reading, after which the text is divided into meaning units that are condensed and abstracted to form sub-themes and main themes; The themes are reflected on in relation to the literature after which a comprehensive understanding is formulated.

Von Zweck et al. [61], who base their views on several classic philosophers, conclude that the advantage of hermeneutics is that it may serve as a strategy to address a broad range of research questions, and it is flexible in interpreting information through a range of sources and theories. Furthermore, as we were four researchers involved in the interpretation process, we felt that the selected method provided us an explicit and practical tool, allowing us to create an enlightened understanding on the unstructured phenomenon through combining our preknowledge in the analysis. Lindseth and Norberg [59] reject the classical phenomenologists' demand for an 'uncontaminated' interpretation, where the researchers should put their preknowledge into brackets. Lindseth and Norberg's phenomenological hermeneutical method emphasizes the preunderstanding as a tool for constantly revising the preunderstandings, while interpreting the experiences expressed in the interview texts. Lindseth and Norberg stress, however, that it is the researchers' judgments about the 
factual data that is important to be put into brackets. This enables the researchers to become open to the essential meanings implicit in the respondent's expressions.

We divided the material between the four researchers, so that each of us had an equal number of transcription text pages to analyze. We read first the interview text several times in order to comprehend its meaning as a whole. (According to Lindseth and Nordberg this phase is called naïve reading). After this, we searched and identified themes, dividing the text in meaning units. These sections were often comprised of several sentences. We started by filtering the main areas of the study, perceptions of health, QoL, and sense of coherence (SOC), into separate sections. After the first rough filtering of about half of the data, the study group compared their interpretations and notes to ensure the validity of the analysis. In cases of disagreement whether an item belonged to the themes or areas of the study, we discussed the items until we came to a shared understanding. This was followed by a detailed analysis within the identified themes of the study in an inductive manner. In order to reach valid interpretation we, once more, read the texts as a whole and reflected our findings towards our previous knowledge and the literature. Thus, the findings emerged as a shared understanding of the phenomena.

\section{Findings}

\subsection{Perceptions of Health, Well-Being, and Quality of Life (QoL)}

The respondents mainly understood the concept of health as "being healthy" and "feeling good". "Well-being" and "QoL" were explained as concepts describing whether a person feels that his/her life is good/satisfactory. We interpreted the respondents' perceptions of these concepts to approach their understanding of the concept of health. The respondents made no distinction between the terms health and QoL.

Pervading in the data was that the terms health, well-being, and QoL were often connected to the respondents' family situation and were seen as collective phenomenon rather than individual or autonomous experiences.

“...Well, of course you feel better yourself when your family feels good and when you know everything is just fine..."

"...And according to our tradition we do not think about our self, our concerns are about our children..."

Furthermore, the respondents seemed to emphasize the external and interpersonal spheres of the QoL.

“...Quality of life is the family, the job, all the things that we discussed earlier (e.g., well-being, good health, that the whole family manages well, to have good economy). Quality of life is to be able to live as a human being. One should not live for someone to trample you down..."

Almost all respondents perceived 'being employed' as one of the most important elements that would influence their health positively. It was regarded as the main source of a good life. Having a job would bring security, better economy and structure to the day, but also important social contacts. Job was not regarded being in relation to exclusive housing or other material things, though. 
“...I'm not aiming high in any way, that I want to be someone special, or that I want to buy this and that. I am living like an ordinary person, I do not want to be poor, but I do not want to be rich either. If I become rich, then I become rich, but it is nothing that I am striving to. So I live like an ordinary person and I am grateful to have my life situation as it is now..."

Rather, having a job was seen in connection to personal development. Work was seen to primarily increase their status as individuals and role models for their children and other young people in the community. Furthermore, work was considered to ensure the security and well-being of the whole family and had a connection to the interviewees' personal sphere by bringing structure to the day. The respondents emphasized that they had realized that the most important bridge to the labor market and to an improved QoL was education. These were only the respondents' perceptions though, as most of them did not have a job, neither a completed education. The respondents made it very clear that they were not satisfied with this deficit in their life. The lack of education and employment was thereby stated as the most important circumstance in need of change, both on an individual level and as for the entire Roma community in order to improve their life chances.

“...Without an education it won't work, everybody knows that. It is not like it was before in the world. Nowadays you have to get an education..."

The respondents described that they put a great deal of effort into convincing their children that there is a connection between well-being, security for the family and a formal education. There are several reasons why many adult Roma in Sweden do not have an education, e.g., Swedish law and regulations in the past, discrimination in school [2], and as some Roma note:

"...why should we go to school when no one wants to employ a Roma anyway? It feels unnecessary and a waste of time..."

It is an interesting contradiction between what is said here and in the quote above - on the one hand education is considered as important, on the other hand, education is perceived meaningless. Ideals and reality seem to clash.

“...You have very few role models; you see very few who succeed within the Roma group. First and foremost, I am the second generation who had the right and possibility to go to school. My parents were of the generation when the law was changed; all of a sudden you had to go to school... That happened pretty recent.... So, we have not yet come very far regarding the awareness of what attending school is supposed to lead to, and of what it provides. We have learned to manage without it and we have survived... besides, so far we have also seen that education does not lead to anything, anyway. One does not get an employment, you know! It's incredibly difficult..."

Social support from family and friends (mainly from their own Roma community), the quality and type of residential area, and the extent of involvement in society emerged as determining the perception of health. Feeling free and secure in a country (the global sphere of QoL) were also perceived as significant elements of health, as well as important values for their lives. By freedom and security, the respondents meant a free choice to participate in social life on equal terms; e.g., to have the right to attend school, to have a job, to live where and how they wish, to be able to move around freely at any time, to keep their integrity and to be themselves, as well as to keep up with their traditions as they wish. 
"...When I go to the center here, then no one watches me or controls what I do, what I buy or what clothes I'm wearing, or what watch I'm wearing or what necklace. They do not watch. Therefore it is better here where I live now, I am more free....”

“...Because in Z, we were very much discriminated against by the group $\mathrm{X}$. We did not have any freedom at all. Always when we went somewhere, or went to the city, we had to constantly watch the clock. We had to be back at home at 7 o'clock, because of these many rules.... they checked which families had much money or who had a good economy, and then they went over there and took their money, properties and so. They just wanted to oppress the Roma..."

Several respondents reported either being, or having been, depressed. Yet, despite depression and diverse medical health problems, lack of education and employment, as well as difficult life events including experienced discrimination and harassment, the respondents perceived their health and QoL as good.

“...Wellbeing and good QoL means that all are doing fine, doing normal. We are not poor and we are not rich, we're fine. We pass by every day, you know. We have clothes, we have food in the fridge, I can go to my school and take a lunch, I can leave my children in school and I feel good about it, I can feel safe. That is quality of life.... To see my children go to school with their friends... That makes my day...."

\subsection{Health, Well-being, and QoL of the Roma from a Salutogenic Perspective}

The respondents talked about health, well-being, and QoL in terms of health as a resource and as an ability to manage life.

“...I am building up my well-being; I'll see, too, that I have a good quality of life that will act as a protection against many adversities. The weaker I am mentally and physically, the easier I might be hit by adversities. Throughout the times when I do not struggle with any adversity, I try to gain as much strength and prosperous as possible..."

“...I actually think that I handle difficult situations quite well. But that's because I'm feeling good, so that I am able to cope with them. Then also, because you are feeling good yourself, right now, you will keep up with it. But if you already are feeling bad when the tough situation comes, then handling a tough situation will be much, much more difficult..."

Concerning manageability, the ways the respondents explained how they handled difficult situations were to think positively and to follow their "survival strategies" over generations. The respondents used the word survival strategies, the deeper content of which remained difficult to understand, but were explained as something to gain strength and developed from experiences of hardship.

“...I think that Roma generally have a very strong survival strategy, most of the Roma are people who do survive, and this is, I think, something that is molded.... you will often find solutions to cope with the day. If you have poor economy, then you will find other solutions, you can e.g., sew a canvas from nowhere, and then you may sell it and you get bread for the day as well. And so it has been... a survival strategy. It is stuck, this survival strategy, with some old traditions, like that, and with the community..." 
The findings indicate that there are different ways to react in a stressful situation. One could either react in an active way, like to go for a walk, talk with friends, drink alcohol, or in some other way try to reduce the stress. Optionally, one could stay passive or be neutral to the stressors, trying to adjust in the situation, e.g., "being strong," "having contact with God," or "following traditions." It seemed important not to lose one's sense of value as a person but still recognizing one's own role in the problem. The passive or neutral approach was perceived by the respondents as positive and seemed to be the most common approach to manage stress.

“...It becomes like that, you are thinking...no worries! When I believe it will all turn out to be fine, then I feel good too. I think you should talk about good things, not bad things. Bad things, I think, will only make you feel worse. If you talk about good things you will feel better..."

Expressions like to "set goals," "test one's limits," "work harder," "taking it easy," "proceeding step by step," and "not giving up" in order to mitigate the experienced tensions were also frequently emerging from the data.

"...You know that you will encounter setbacks, but of course, the worse the health, the worse the well-being, and the harder it will be to face the adversity. When you face setbacks, then you can compare the setback with earlier setbacks, and then maybe it turns out that this setback is nothing compared to what you already have experienced, and then you do not take it seriously...I mean, that it does not hit you that much. Or perhaps, if you feel good, and then a setback strikes you, then you think like 'I am feeling fine'. My positive feeling weights more than this adversity, and so I will overcome it..."

Destructive ways to manage stressors (e.g., gambling, smoking, drinking alcohol) were common among the male respondents even though they were not perceived to abolish or ease their stressors, but instead could give rise to new problems.

“...When I smoke I am completely relaxed, so I do not think about problems. When I'm watching TV, I do not think about the problems and so. That's the reason why I smoke and why I started smoking, and also because I have had some problems with the police, and other problems out there and problems at home.... After 5-6 years I found myself smoking every day and it was too much for me. Then I felt a bit ... I could not breathe, I could not run as fast as before. Before, I had a good condition; I could play a lot of football..."

Specific to men in connection with the stories about managing difficult events, was also the tendency to stress their better qualities: e.g., "I am a good man..." "I have a lot of friends..." and "I am a hardworking man..." However, for many respondents, the ultimate coping strategy was turning to God. The respondents told that the Roma people are often religious.

“...I did nothing really....I knew that it came from God, and I was just waiting: what more will happen now. ... It was God who helped me.... It's God first, then comes the relatives..."

Still, what was considered most crucial to overcome stress and difficult life situations, were fellowship and talking with friends and family to process personal problems.

“...When things get hard, we (the Roma) are never alone anyway. In tough situations, it is the whole family (including my five siblings, and my relatives in town X) that keeps in touch whenever someone in the family is struggling. I get back to them whenever they are in need, as well...” 
The respondents' children were perceived to have the biggest impact in making the respondents' life meaningful besides the possibility to get an education and to achieve the goals set by the school (for those who went to school), followed by a feeling of success, motivated the respondents and influenced whether they perceived life as meaningful. The respondents stated that life is full of various challenges and that you have to be prepared for adversities. Some believed that what happens in life is destined and that you cannot influence it yourself (i.e., out of the control of the individual: "it is not possible to change things", "everything happens for a reason that you cannot influence", "life is a chain of events", "letting it be without thinking about it so much", "it is written in the Bible", and "war"). However, the most common way to comprehend the world and explain what was happening all around was the perception that it is only you yourself who can influence the situation (e.g., "explaining to oneself the meaning of a situation", "understanding the importance of education"," thinking positively", "learning from mistakes", "understanding it is one's own fault that the problem exists", "children understand their parents" commitment to them", and "sacrificing now for a better future").

“...You have to find yourself in the situation, so that, you must make the best of the situation, regardless of what it is. One must find the positive in the negative, and then you have to build on that.... It's hard. It's very difficult but my experience has shown that it is possible..."

\subsection{Stress Factors}

The hectic pace of life was experienced as most stressful by half of the respondents, both men and women. The female respondents claimed to have a stressful life and no time for themselves, free from housekeeping, children, or parents/parents in law. They felt that some spare time would increase their QoL. Those male respondents who had a job described their employments and positions as unsecure and therefore stressful.

“...I worked there for two years then I couldn't do it anymore. I was too tired. I never got any regular or fixed jobs. They just called whenever they needed me, and I could never say no as I did not know when they would need me the next time...."

"...I come home from work, pick up the kids from daycare, fix something to eat, and then I go to school, The whole time, even in free time, you do not feel free, I can never relax..."

The respondents were afraid that if they were absent from the workplace they would be replaced. Violence and bullying, (particularly bullying of the respondents' children at school or play yard), discrimination, and threatening neighbors, were also mentioned as stressors, as well as issues like divorce, death, and disease of people close to them, and also daily small dilemmas. However, for those who had experienced war and persecution in their home country, the constraints of leaving their properties, friends, and everything they had built their life on, were mentioned as the most serious stress factors.

“...When I left my home country, it felt like we were going nowhere. You are leaving everything you have, the family and the little home you had.... You do not know where you are, who you will meet, what will happen to those you have left back home, or what will happen at all. You have no contacts, nothing..." 


\section{Discussion on the Core Findings}

We assumed that the Sense of Coherence (SOC) is a global life orientation [42] with people's abilities to comprehend what is happening around them, to manage the situations, and to find meaning in these situations. Against all odds the interviewed Roma people reported to hold a good subjective health, feel well, and have a good quality of life. The Roma saw "health" as being healthy or to feel good, and considered health as an ability to manage life and as a resource for good life.

The respondents saw health, well-being, and QoL through the perspective of their families. The family was number one in almost all the respondents' lives with the exception of those who set God/religion before the family. If the respondent's family was doing fine, then the respondent was also feeling good. Whenever there were problems of some kind, they reported to turn to their family. Roma people belong to a collectivist culture. Collectivist cultures do tend to, according to Diener [55], consult with friends, family, and their norms, when valuing their lives and whether they consider themselves being satisfied. Likewise, people in a collectivist society may be more likely to sacrifice their personal happiness to do their duty. The sense of satisfaction from doing the right thing, however, may feel more rewarding when the doing of the right thing is congruent with the person's own desires and does not require explicit sacrifices [55]. The respondents reported that material goods would not make them happier, if only they had their basic needs fulfilled, like housing and food. What were experienced as important were non-material aspects such as family, education, and work. This cultural aspect supports the view of WHO [11], which views QoL towards the context of the culture, value system, and society where the individual lives. The level of QoL and well-being is set by the satisfaction of non-material needs rather than material needs. An explanation for the reported good health, well-being, and QoL, might also be found in the Roma people's strong social ties with their core and extended family, which probably served as general resistance resources [42] towards stress and difficulties in life.

According to the results, having a job and a completed education verified with a certificate, or at least an access to education, were further core factors of health (while they also simultaneously say that there is no point to educate themselves, as the employers do not seem to be willing to employ Roma). Nevertheless, even though the majority of the informants were lacking these crucial elements, they reported that their health and QoL were good, which according to Albrecht and Devlieger [56] could be seen as a disability paradox. Diener [55] explains the disability paradox with the concept of 'adaptation': As people develop successful strategies for coping with life events, they adapt to the new situation; they find a new meaning in the situation and consequently, after a while the new situation is not influencing their perceptions of subjective well-being or QoL anymore. Huber et al. [45] define health as being a person's ability to self-manage and adapt according to the circumstances. Accordingly, a person with bad objective health, e.g., disabilities or illness, actually may perceive good health if he manages to adapt and cope with his situation. Consequently, if health is to adapt and cope with various situations, then it also is a resource for managing life [43]. Health seen as a resource and the ability to adapt and self-manage are, as we see it, the explanations for the disability paradox.

Another question is whether, it is possible to adapt to new circumstances if the person remains passive or neutral, which were shown to be some of the coping strategies of the interviewed Roma? If a person does not take action in order to adapt, he might remain in an unwanted situation and 
consequently, perceive his health and QoL as unsatisfactory. Health might still be a resource, but the passive person does not know how to make use of, or release it, in order to adapt or cope.

Being employed was a crucial factor for the good life and subjective health. In the Swedish society, being employed is an indicator of objective well-being. According to the society's expectations, all people of working age ought to have a job. If this is not the case, you are expected to feel bad. Eid and Diener [49] found that people may respond to subjective well-being scales in socially desirable ways. If they believe that happiness is normatively appropriate, they may report that they are happier than other types of assessments may indicate. Being employed or not influences the person's subjective well-being as it has an impact on the personal sphere, the person's mood, and feelings. Van Cleemput et al. [62] show that Roma people also tend to normalize and accept having poor health. So, it might be that unemployment has become a "normal" condition, in which the Roma have gotten used to. Unemployment among Roma in Sweden is high, estimated as 90\% by SOU 2010 [2], and has been so for generations. Consequently, it might be that being unemployed does not have the same degree of impact on Roma people's subjective well-being as it does on non-Roma (in addition, according to the respondents, remaining unemployed was sometimes a better option than being a target for discrimination and harassment at the work place.) We want to point out, however, that this does not mean that the Roma do not care about being unemployed. One of our core findings distinctly shows that the respondents do perceive employment as essential for health, well-being, and QoL. Even though the respondents were not happy with their unemployment, they had learned to cope with it. Moreover, Eid and Diener [49] found that situational factors (in this case unemployment) usually pale in comparison with long-term influences on well-being measures (in this case diverse coping strategies such as support from social networks, "survival strategies" and adaptability).

Among non-Roma, there is a general understanding that when the Roma people talk about 'freedom', they mean that they do not need to fulfill a citizen's obligations, and that they do not need to follow laws and regulations (e.g., going to school, having permanent settlements, and paying taxes). This study, however, shows that this is just a prejudice, which the respondents meet and try to overcome. By freedom, the respondents meant a free choice to participate in social life on equal terms. Our results regarding this issue are also in line with the findings of a study on Roma adolescents' perceptions on health and QoL [37].

When it comes to the respondents' view that freedom and security are significant factors of a good life, we need to bear in mind not only experiences of war, but also the long devastating history of the Roma people living with persecution and exclusion. Discrimination and racism have proven to have a negative impact on health $[15,17,18,63,64]$. The question remains, how can it be that Roma people perceive their health and QoL to be good? How is it ever possible to adapt to a situation of almost daily experiences of discrimination and exclusion? The answer might partly be related to the measurements used. Most of the studies measuring minority health have (e.g., $[15,17])$ been based on positivist quantitative instruments designed by the non-Roma society, where the 'standards' of objective health come from. Using these instruments the research results show mainly poor health among Roma. Our study was, in contrast, based on subjective perceptions on health, well-being, and QoL and searched for the respondents own evaluations on what is health for them personally. The objective and the subjective perceptions constituted significant differences and, as discussed above, a health paradox. Our suggestion is that this paradox is connected with the fact that the Roma are a 
collectivist group. The Roma perceive the concept of health as a collective phenomenon. Thus, it is the collective health that counts. When being within their Roma community, the respondents felt good, safe, and satisfaction with their lives. The respondents expressed a strong sense of basic trust in their family and relatives, which may be explained by the tight social bonds within Roma families and communities. The internalized traditions, values, customs, etc., are assets (cultural capital) that function as a buffer against stress and difficult life situations within the Roma community, become less of a value outside the Roma society. The "inside" world was perceived as reliable and predictable. However, many of the Roma respondents had been met with negative attitudes by the non-Roma society, which they claimed to be the reason why their trust in the non-Roma people and society was low or sometimes even totally lacking. So the question remains, how sustainable is the perception of feeling good and satisfaction with QoL, when the Roma leaves the secure Roma community network and enters the "outside world"?

\section{Conclusions}

According to the results, having a job and an education were core factors of health for the interviewed Roma. The respondents saw health, well-being, and QoL through the perspective of their entire family rather than through individual experiences.

Our findings indicate that the respondents viewed health as a resource [43] and an ability to self-manage [45,55]. The Roma people have, and probably will continue to survive, with those survival strategies, which they have developed throughout decenniums. It seems obvious that the strong sense of community, staying close to their families and social network, as well as holding on to traditions, are significant parts of the coping mechanism behind the paradox that the respondents in our study, against all odds, perceived a good subjective health, well-being, and quality of life.

In the material, it could also be seen how the respondents went back and forth between the inside and outside worlds, and how their health indicators differed depending on the context they spoke of. At the same time as they described health problems, they argued that they have a good subjective health and quality of life. Not only can this be understood as a consequence of the collectivist identity as such, but also how this also comes into play in the interview situation with its specific mix of inside and outside worlds. The interviewer represented the outside world, but the interview also gave the opportunity for the interviewees to show and take pride of their inside worlds. This pride should not be neglected. What did the Roma interviewees want to communicate with this? This probably indicates the problems of everyday life of the collective, but also the strength and pride of their self-identity. Declaring yourself healthy and having a good quality of life, regardless of the obvious stress of the life-situation, is also a way of telling the researcher - as a representative of the outside world — that it is not with the Roma people that the problems lie. The problems, and their health consequences, are parts of the outside world. It is therefore there that the change should come from. The issue of declaring health status here, thus, also takes place within the process of identity construction.

\section{Limitations of the Study and Implications for Future Action}

Some limitations of the study that are worth reflecting on are concerned with the epistemological question - the relation between the Roma respondents and the non-Roma interviewers. In the interview 
situation as such, the Roma respondents were positioned in an unequal power relation; they belonged to a national minority group and many of them were unemployed. On the other hand, the interviewers were researchers belonging to the majority society. This, in addition to the Roma community's learned mistrust towards the Swedish society and its members might have influenced the interviewees' responses. We found that the respondents portrayed their views on their health and well-being as somehow paradoxical, but also by directing the attention towards social aspects rather than clinical ones. They expressed work, education, belonging and family relationships as more important for well-being than clinically observed ill-health or any health/risk behavior (smoking, alcohol use, etc.). We consider this as an important finding, which the social and public health professionals should be aware of when planning future interventions and policies regarding efforts to tackle social exclusion of Roma people in Europe.

\section{Authors' Contributions}

LEK designed and coordinated the study and participated in the data collection, analysis and writing the article. KC participated in the data collection, analysis, and writing the article. FS participated in the analysis of the data and helped to draft the manuscript. AA participated in the data collection and analysis and helped to draft the manuscript. All authors read and approved the final manuscript.

\section{Acknowledgments}

The research was supported by the University West. The authors thank the Roma communities in Västra Götaland, Sweden, for their engagement and contribution in the study.

\section{References}

1. Hancock, I. Danger! Educated Gypsy: Selected Essays; University of Hertfordshire Press: Hertfordshire, UK, 2010.

2. SOU. Romers rätt—En strategi för romer i Sverige (in Swedish); Statens offentliga utredningar SOU 2010:55; Elanders: Stockholm, Sweden, 2010.

3. European Commission. The Situation of Roma in an Enlarged European Union; Directorate-General for Employment and Social Affairs: Luxembourg, Luxembourg, 2004.

4. Montesino Parra, N. Zigenarfrågan: Intervention och Romantik (in Swedish). Ph.D. Thesis, University of Lund, Lund, Sweden, 2002.

5. Cederberg, I. Född Fördömd, Romerna-Ett Europeiskt Dilemma (in Swedish); Leopard förlag: Stockholm, Sweden, 2010.

6. Montesino, N. Romer $i$ Svensk Myndighetspolitik-ett Historiskt Perspektiv (in Swedish); Meddelanden från Socialhögskolan; University of Lund: Lund, Sweden, 2010.

7. Palosuo, L. Inventering av forskningen om romer $i$ Sverige (in Swedish); University of Uppsala: Uppsala, Sweden, 2009.

8. Palmroth, K.; Hermansson, H.-E. Socialt medborgarskap (in Swedish). Invandr. Minor. 2006, 3, 12-15. 
9. European Council. Framework Convention for the Protection of National Minorities and Explanatory Report; European Council: Strasbourg, France, 1995.

10. DO. Discrimination against Romanies in Sweden-A Report on the DO Project in the Years of 2002 and 2003 on Counteracting and Forestalling Ethnic Discrimination against Romanies; Reports of the Swedish Equality Ombudsman. Stockholm, Sweden, 2003.

11. WHO. Health Promotion Glossary; World Health Organization: Geneva, Switzerland, 1998.

12. Popay, J.; Williams, G.; Thomas, C.; Gatrell, T. Theorising inequalities in health: The place of lay knowledge. Sociol. Health Illness 1998, 20, 619-644.

13. Popay, J.; Escorel, S.; Hernández, M.; Johnston, H.; Mathieson, J.; Rispel, L. Understanding and tackling social exclusion: final report to the WHO Commission on Social Determinants of Health; Report of the Social Exclusion Knowledge Network; World Health Organization: Geneva, Switzerland, 2008.

14. Pierson, J. Tackling Social Exclusion, 2nd ed.; Routledge: London, UK and New York, NY, USA, 2010.

15. Wiking, E.; Johansson, S.-E.; Sundquist, J. Ethnicity, acculturation, and self reported health. A population based study among immigrants from Poland, Turkey, and Iran in Sweden. J. Epidemiol. Community Health 2004, 58, 574-582.

16. Williams, D.R.; John, D.A.; Oyserman, D.; Sonnega, J.; Mohammed S.A.; Jackson J.S. Research on discrimination and health: An exploratory study of unresolved conceptual and measurement issues. J. Inf. 2012, 102; 975-978.

17. Pascoe, E.A.; Smart Richman, L. Perceived discrimination and health: A meta-analytic review. Psychol. Bull. 2009, 135, 531-554.

18. Harris, R.; Martin, T.; Jeffreys, M.; Waldegrave, K.; Karlsen, S.; Nazroo, J. Racism and health: The relationship between experience of racial discrimination and health in New Zealand. Soc. Sci. Med. 2006, 63, 1428-1441.

19. Zeman, C.L.; Depken, D.E.; Senchina, D.S. Roma health issues: A review of the literature and discussion. Ethn. Health 2003, 8, 223-249.

20. Braham, M. The Untouchables: A Survey of the Roma People of Central and Eastern Europe: A Report to the Office of the United Nations High Commissioner for Refugees; Office of the United Nations High Commissioner for Refugees (UNHCR): Geneva, Switzerland, 1993.

21. Van Cleemput, P.; Parry, G. Health status of gypsy travellers. J. Public Health 2001, 23, 129-134.

22. Parry, G.; Van Gleemput, P.; Peters, J.; Walters, S.; Thomas, K.; Cooper, C. Health status of gypsies and travellers in England. J. Epidemiol. Community Health 2007, 61, 198-204.

23. Hussey, R. Equal opportunities for Gypsies. Public Health 1989, 103, 79.

24. Trnka, L.; Hejdova, E. Surveillance of tuberculosis in the Czech Republic in 1991. Casopís lékaru českých 1993, 132, 401.

25. Thomas, J.D. Gypsies and American medical care. Ann. Internal Med. 1985, 102, 842.

26. Thomas, J.D.; Doucette, M.M.; Thomas, C.C.; Storckle J.D. Disease, lifestyle, and consanguinity in 58 American Gypsies. Lancet. 1987, 330, 377-379.

27. Sutherland, A. Gypsies and health care. West. J. Med. 1992, 157, 276. 
28. Bodner, A.; Leininger, M. Transcultural nursing care values, beliefs, and practices of American (USA) Gypsies. J. Transcult. Nurs. 1992, 4, 17-28.

29. Braga, C. Transcultural nursing and beliefs: Values and practices of the Gypsy population. Rev. Escol. Enferm. USP 1997, 31, 498-516.

30. Binnie, G.A. The health of Gypsies: Problem of caring for travellers is British, not just European. Br. Med. J. 1998, 316, 1824-1825.

31. Zonda, T.; Lester, D. Suicide among Hungarian gypsies. Acta Psychiatr. Scand. 1990, 82, 381-382.

32. Semerdjieva, M.; Mateva, N.; Dimitrov, I. Sexual culture of gypsy population. Folia Med. 1998, 40, 72-75.

33. Feder, G.S.; Vaclavik, T.; Streetly, A. Traveller Gypsies and childhood immunization: A study in east London. Br. J. General Pract. 1993, 43, 281-284.

34. Miszei, K.; Slay, B.; Mihailov, D.; O’Higgins, N.; Ivanov, A. Avoiding the Dependency Trap; UNDP: Bratislava, Slovakia, 2003.

35. FSG (Fundación Secretariado Gitano). Health and the Roma Community, Analysis of the Situation in Europe; FSG: Madrid, Spain, 2009.

36. The Swedish National Institute of Public Health (Folkhälsoinstitutet). Hur mår Sveriges nationella minoriteter (in Swedish)? Folkhälsoinstitutet: Stockholm, Sweden, 2010.

37. Crondahl, K.; Eklund, L. Perceptions on health, well-being and quality of life of Balkan Roma adolescents in West Sweden. Romani Stud. 2012, 22, 153-174.

38. Hassler, S.; Eklund, L. Sense of coherence and self-reported health among Roma people in Sweden-a pilot study. Int. J. Circumpolar Health 2012, 71, 18438.

39. Rodell Olgac, C. Den Romska Minoriteten i Majoritetssamhällets Skola: Från Hot Till Möjlighet (in Swedish). Ph.D. Thesis, University of Stockholm, Stockholm, Sweden, 2006.

40. Eklund, L. Empowerment och delaktighet hos romer i Västsverige (in Swedish). Svenska ESF rådet. Göteborg, Sweden, 2010. Available online: http://www.esf.se/sv/Projektbank/Behallare-forprojekt/Vastsverige/Empowerment-och-delaktighet-hos-romer-i-Vastsverige-genomforande/ (accessed on 3 June 2013).

41. Berntsson, L. Health and Well-being of Children in the Five Nordic Countries in 1984 and 1996; Nordic School of Public Health: Göteborg, Sweden, 2000.

42. Antonovsky, A. Health, Stress, and Coping; Jossey-Bass: San Francisco, CA, USA, 1979.

43. WHO. Ottawa Charter for Health Promotion. World Health Organisation: Geneva, Switzerland, 1986.

44. Williams, L.; Labonte, R. Changing health determinants through community action: Power, participation and policy. Promot. Educ. 2003, 65-71.

45. Huber, M.; Knottnerus, A.; van der Horst, H.; Jadad, A.R.; Kromhout, D.; Leonard, B.; Lorig, K.; Loureiro, M.I.; van der Meer, J.W.M.; Schnabel, P.; et. al. How should we define health? Br. Med. J. 2011, 343, d4163.

46. Eriksson, M. Unravelling the Mystery of Salutogenesis: The Evidence Base of the Salutogenic Research as Measured by Antonovsky's Sense of Coherence Scale; Folkhälsan Research Centre: Turku, Fenland, 2007. 
47. Lindström, B. The Essence of Existence: On the Quality of Life of Children in the Nordic Countries-Theory and Practice in Public Health. Nordic School of Public Health: Göteborg, Sweden, 1994.

48. Diener, E.; Emmons, R.A.; Larsen, R.J.; Griffin, S. The satisfaction with life scale. J. Personal. Assess. 1985, 49, 71-75.

49. Eid, M.; Diener, E. Global judgments of subjective well-being: Situational variability and long-term stability. Soc. Indic. Res. 2004, 65, 245-277.

50. Diener, E.; Emmons, R.A. The independence of positive and negative affect. J. Personal. Soc. Psychol. 1984, 47, 1105.

51. Gasper, D. Understanding the diversity of conceptions of well-being and quality of life. J. Socio-Econ. 2010, 39, 351-360.

52. Andrews, F.M.; Withey, S.B. Social Indicators of Well-being: Americans' Perceptions of Life Quality; Plenum Press: New York, NY, USA, 1976.

53. Pavot, W.; Diener, E. Review of the satisfaction with life scale. Psychol. Assess. 1993, 5, 164.

54. Shin, D.C.; Johnson, D.M. Avowed happiness as an overall assessment of the quality of life. Soc. Indic. Res. 1978, 5, 475-492.

55. Diener, E. Subjective well-being: The science of happiness and a proposal for a national index. Am. Psychol. 2000, 55, 34-43.

56. Albrecht, G.L.; Devlieger, P.J. The disability paradox: High quality of life against all odds. Soc. Sci. Med. 1999, 48, 977-988.

57. Biernacki, P.; Waldorf, D. Snowball sampling: Problems and techniques of chain referral sampling. Sociol. Methods Res. 1981, 10, 141-163.

58. Bryman, A. Social Research Methods; OUP: Oxford, UK, 2012.

59. Lindseth, A.; Norberg, A. A phenomenological hermeneutical method for researching lived experience. Scand. J. Caring Sci. 2004, 18, 145-153.

60. Ricoeur, P. Interpretation Theory: Discourse and the Surplus of Meaning; TCU Press: Fort Worth, TX, USA, 1976.

61. Von Zweck, C.; Paterson, M.; Pentland, W. The use of hermeneutics in a mixed methods design. Qual. Rep. 2008, 13, 116-134.

62. Van Cleemput, P.; Parry, G.; Thomas, K.; Peters, J.; Cooper, C. Health-related beliefs and experiences of Gypsies and Travellers: A qualitative study. J. Epidemiol. Community Health 2007, 61, 205-210.

63. SOU. Integrationens svarta bok. Agenda för jämlikhet och social sammanhållning (in Swedish); Statens offentliga utredningar SOU 2006:79; Fritzes: Stockholm, Sweden, 2006.

64. Williams, D.R.; Neighbors, H.W.; Jackson, J.S. Racial/ethnic discrimination and health: Findings from community studies. J. Inf. 2003, 93, 200-208.

(C) 2013 by the authors; licensee MDPI, Basel, Switzerland. This article is an open access article distributed under the terms and conditions of the Creative Commons Attribution license (http://creativecommons.org/licenses/by/3.0/). 